\title{
Careful preoperative planning of aortic valve surgery - impact of echocardiography and CT parameters
}

\section{(D) Josip Varvodić1*, (DDubravka Šušnjar', (D) Ivana Jurin', (D) Jasenka Grgurić (1D)Boris Starčević1, (D)Frane Paić2 (DIgor Rudež ${ }^{1}$}

'University Hospital Dubrava, Zagreb, Croatia

${ }^{2}$ University of Zagreb, School of Medicine, Zagreb, Croatia

RECEIVED:

September 4, 2019

ACCEPTED:

September 16, 2019

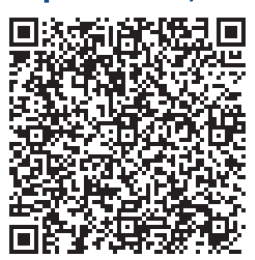

$\square$ Cardiologia Croatica 2019;14(9-10):228.
KEYWORDS: aortic valve surgery, aortic valve stenosis, calcium score. CITATION: Cardiol Croat. 2019;14(9-10):228. | https://doi.org/10.15836/ccar2019.228

*ADDRESS FOR CORRESPONDENCE: Josip Varvodić, Mesnička 7, HR-10000 Zagreb, Croatia. Phone: +385-99-3553-909 / E-mail: josip.varvodic@gmail.com

ORCID: Josip Varvodić, https://orcid.org/0000-0001-6602-699X • Dubravka Šušnjar, https://orcid.org/0000-0002-9644-9739 Ivana Jurin, https://orcid.org/0000-0002-2637-9691 • Jasenka Grgurić, https://orcid.org/0000-0002-0876-6217 Boris Starčević, https://orcid.org/0000-0002-3090-2772 • Frane Paić, https://orcid.org/0000-0001-9688-8582 Igor Rudež, https://orcid.org/0000-0002-7735-6721

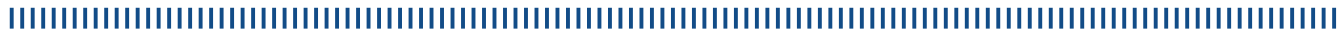

Objective: We can observe an increase in incidence and prevalence of patients with aortic valve stenosis in the general population. The gold standard in aortic valve therapy is aortic valve replacement. Preoperative planning is essential for good outcomes, as the severity of stenosis and calcifications can sometimes be extremely progressive and even involve the aortic root and ascending aorta. There is not enough research on comparation of CT scan analysis of aortic valve stenosis and echocardiography which is the golden standard of disease diagnosis. ${ }^{1-3}$

Patients and Methods: We have analyzed 88 patients [age: $70.01 \pm 9.066$ (mean $\pm S D)$; female: $n=45,51.1 \%$ ], Among the patients, 12 had bicuspid aortic valve leaflet structure while the rest of the patients ( $\mathrm{n}=76$, 86.4\%) exhibited TAV stenosis. Degree of aortic stenosis was assessed according to mean pressure gradient (MPG), peak pressure gradient (PPG), aortic valve area (AVA) indexed aortic valve area (AVAi) and maximum speed through aortic valve (Vmax). These were compared with calcium score (AVCS) calculated from CT scan. All of these patients were observed in the operating room during surgery and valves analyzed after explantation. All of the patients underwent aortic valve replacement.

Results: Average AVCS values (median + IQ range) were 3306.3 (1995.4 - 4820.6) [female: 2215 (1463.35 - 3372.85); male: 4093.5 (3133.3 - 5274.4). Average AVCS values for BAV patients were 3063.5 (3323.125 4868.9) and 3106.55 (1965.375) - 4780.125) for TAV patients. There were significant correlations between AVCS and AVAi (Spearman's $\rho=-0.24, P=0.025)$, PPG $(\rho=0.38, P<0.001), M P G(\rho=0.36, P=0.001) \mathrm{V} \max (\rho=$ $0.37, P<0.001)$ and gender $(\rho=0.485, P<0.001)$ while AVA values showed no significant correlation with AVCS ( $\rho=-0.066, P=0.540)$. Overall survival was similar not depending of severity of calcifications and stenosis, however clamp time and surgery time were longer for patients with severely calcified valves which means calcium scoring as a parameter should also be taken in consideration during preoperative planning.

Conclusion: Careful preoperative planning is essential for good outcome of surgery, here we have proven the connection between echocardiography parameters of aortic stenosis and calcium score calculated by CT scan.

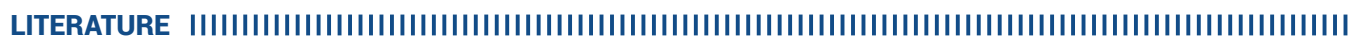

1. Pawade T, Clavel MA, Tribouilloy C, Dreyfus J, Mathieu T, Tastet L, et al. Computed Tomography Aortic Valve Calcium Scoring in Patients With Aortic Stenosis. Circ Cardiovasc Imaging. 2018 Mar;11(3):e007146. https://doi.org/10.1161/CIRCIMAGING.117.007146

2. Reddy S, Trivedi R, Mueller J, Mickus T, Shah M. Aortic valve calcium score: a strong predictor of severity of aortic stenosis in patients with low flow, low gradient reduced ejection fraction population. J Am Coll Cardiol. 2009;73(9 Suppl 1):1648. https://doi.org/10.1016/S0735-1097(19)32254-5

3. Shimizu K, Yamamoto M, Koyama Y, Kodama A, Sato H, Kano S, et al. Usefulness of routine aortic valve calcium score measurement for risk stratification of aortic stenosis and coronary artery disease in patients scheduled cardiac multislice computed tomography. Int J Cardiol Heart Vasc. 2015 0ct 31;9:95-99. https://doi.org/10.1016/j.ijcha.2015.10.008 